\title{
Correlates of traumatic brain injury among juvenile offenders: A multi-site study
}

\author{
MICHAEL G. VAUGHN ${ }^{1}$, CHRISTOPHER P. SALAS-WRIGHT ${ }^{2}$, \\ MATT DELISI ${ }^{3}$ AND BRIAN PERRON ${ }^{4}$, ${ }^{1}$ School of Social Work, Saint \\ Louis University, St Louis, MO, USA; ${ }^{2}$ University of Texas, Austin, TX, \\ USA; ${ }^{3}$ Iowa State University, Ames, IA, USA; ${ }^{4}$ University of Michigan, Ann \\ Arbor, MI, USA
}

\section{ABSTRACT}

Background There is some evidence that antisocial individuals, including young delinquents, are significantly more likely than people in the general population to incur a traumatic brain injury (TBI). Extant studies are hampered by methodological limitations, such as small sample sizes, lack of control for confounding effects, and use of single sites and may lack representativeness.

Hypothesis The hypothesis for this study is that young offenders with a history of TBI will not only be at higher risk of impulsivity and negative emotionality than their non-injured peers but also that those with TBI will have had more previous victimisation experiences.

Methods Data from two sites (Philadelphia, PA and Phoenix, AZ) in a substantial longitudinal, prospective study - the Pathways to Desistance Study - were used to compare young people (average age 16 years) who reported TBI with those who did not. Independent variables were behavioural, criminogenic and psychosocial measures.

Results Male youths were about twice as likely as young females to report TBI. Such injury was associated with higher impulsivity and negative emotion ratings, even after allowing for potentially confounding factors, including sex. In addition, TBI was independently associated with self-reported experience of victimisation.

Conclusions/implications This extends the generalisability of earlier suggestions of a relationship between TBI and offending, and various factors thought likely to mediate the relationship. The implications are, thus, that it is likely to be of practical value to screen young people who get into the criminal justice system for a history of TBI, and thus to allow for more specific tailoring of interventions to reduce the range of associated problems, including likely reoffending. Copyright (C) 2014 John Wiley $\mathcal{E}$ Sons, Ltd. 


\section{Introduction}

Traumatic brain injury (TBI) has been defined as a 'head injury involving loss of consciousness/amnesia with ongoing cognitive or social impairment' (Craswell et al., 2004, p. 426). TBI is costly, resulting in over one million emergency department visits and 50,000 deaths annually (Faul et al., 2010). According to the National Center for Injury Prevention and Control, 15- to 19-year-olds and children under the age of 4 years are at the highest risk for suffering TBI (Langlois et al., 2006). Males are about twice as likely as females to suffer a TBI (McGuire et al., 1998; McKinlay et al., 2008). In the general adult population, studies of TBI indicate that the average prevalence is of the order of $12 \%$ (Frost et al., 2013). The ranges recorded across these studies, however, suggest substantial measurement variance.

Given their frequent exposure to risks from such events as violent encounters, it would be expected that offenders would have high rates of TBI relative to the general population. Two meta-analyses have examined its prevalence in offender populations. Shiroma et al. (2010) found a prevalence of about 60\% (95\% CI = 48.1-72.4) among young offenders, whereas (Farrer et al. (2012) revealed from nine studies of juvenile offenders that about $30 \%$ of them have a TBI. Comparative analysis of a subset of five studies with control groups of non-juvenile offenders indicated that young offenders were more than three times more likely $(\mathrm{OR}=3.4)$ to have a TBI.

Although research is beginning to establish the prevalence of TBI among juvenile offenders, there are still few studies of its correlates. In a study of incarcerated youths in Missouri, Perron and Howard (2008) found that those with a history of TBI were more likely to be male, report greater distress (e.g. anxiety, depression and hostility) and higher levels of substance abuse and criminal activity in the preceding year. Williams et al. (2010), in a study of 186 young offenders in England, found that TBI was associated with more violence (two or more convictions on average), psychiatric distress and cannabis abuse. In a separate English study with 61 young male offenders, Davies et al. (2012) identified a trend toward earlier onset of offending, more convictions and alcohol use in relation to severity of TBI. Taken together, however, these studies are hampered either by their small sample sizes and consequently low capacity to detect effects or execute multivariate analyses to check for confounding variables, or by their relegation to single sites that may lack representativeness.

\section{Theoretical context}

We consider TBI to be nested within two major theories of antisocial and criminal behaviour. First, Moffitt's (1993, 2003) dual taxonomy of adolescencelimited and life-course persistent offending, which posits that most young people will engage in some form of mild problem behaviours during adolescence, but a 
small subset (more usually male) will continue to offend across the life-course. She found these life-course persistent offenders to be characterised by neuropsychological deficits and difficult temperaments (behaviour disinhibition and negative emotionality), in turn fuelling continued life problems. There is strong empirical support for Moffitt's taxonomy across various data sources (Barnes and Beaver, 2010; Farrington et al., 2009; Jennings and Reingle, 2012; Moffitt et al., 2002; Vaughn et al., 2011a, 2011b). One investigation of head injuries using the Pittsburgh Youth Study found few differences between adolescent-limited and life-course persistent offenders except that the number of times knocked unconscious was higher among the persistently offending youths (Raine et al., 2005).

Secondly, Gottfredson and Hirschi's general theory of crime (1990) emphasised low self-control as the pre-eminent mechanism for crime. People with low self-control are impulsive, insensitive, negatively emotional risk takers who have difficulty meeting basic family, school or work responsibilities. Numerous empirical studies across community as well as clinical samples demonstrate support for this general theory (DeLisi, 2011; DeLisi and Vaughn, 2008; de Ridder et al., 2012; Pratt and Cullen, 2000; Vaughn et al., 2009).

Consistent with both of these theoretical perspectives, TBI among juvenile offenders should be associated with both greater levels of impulsivity and antisocial behaviour and victimisation and negative emotionality. Two mechanisms may account for the link. The first is that neuropsychological deficits, including self-control deficits, are a result of a TBI. An equally, if not more probable, mechanism is that TBI is a result of pre-existing temperament-based impulsiveness and negative emotionality such as hostility and anger, then, in turn, associated with a greater probability of exposure to violent encounters.

We aimed to test the hypotheses that not only will young offenders with a history of TBI be at higher risk of impulsivity and negative emotionality than their non-TBI peers but also those with TBI will have had more previous victimisation experiences.

\section{Method}

\section{Sample and procedures}

We analysed data from the baseline interviews from the Pathways to Desistance study (Schubert et al., 2004). Study participants were 14- to 18-year-olds who had been found guilty of a serious criminal offence in the juvenile or adult court systems in Phoenix, Arizona or Philadelphia, Pennsylvania. Serious criminal offences included most felonies, except for minor property crimes, as well as misdemeanor sexual assault and weapons offences. Given the disproportionate percentage of juvenile arrests associated with drug use, the proportion of study participants who were arrested due to drug offences was limited to no more than $15 \%$ of the male sample so as to allow for a greater diversity of offenders. The 
much smaller numbers of female offenders who met study criteria were all deemed eligible, regardless of whether their adjudicated offense was drug-related. On average, the baseline interview was conducted approximately 40 days after their initial adjudication or decertification hearing. More details of the study design and data collection procedures are available at the Pathways to Desistance website (http://www.pathwaysstudy.pitt.edu/) and in published methodological manuscripts (Chung et al., 2007; Mulvey and Schubert, 2012; Schubert et al., 2004).

A total of 1354 adjudicated adolescents completed the baseline survey between November 2000 and January 2003. At baseline, their mean age was 16 years $(\mathrm{SD}=1.14)$; most were male $(1170,86.4 \%)$, although a substantial proportion were female 184, 13.6\%). The racial/ethnic makeup of respondents was diverse: roughly one in five respondents was non-Hispanic white $(274,20.2 \%)$, two in five African American $(51,41.4 \%)$, one in three Hispanic $(454,33.5 \%)$ and a small percentage was categorised as 'other' $(65,4.8 \%)$. In terms of criminal offending, just under half of the sample reported that their most serious offence was a crime against the person $(596,44 \%)$. The remainder reported that their most serious offence was a property offence $(339,25 \%)$, drug offence $(217,16 \%)$, weapons offence $(135,10 \%)$ or another type of offence $(54,4 \%)$.

\section{Measures}

\section{Traumatic brain injury}

Respondents were asked whether they had ever experienced a head injury, which caused unconsciousness or needed medical attention. Respondents who said yes $(N=411,30.35 \%)$ were coded as 1 and those who said no $(N=943,68.65 \%)$ were coded as 0 .

\section{Substance use}

Substance use was measured by rating yes/no to use of 10 substances during the previous year $(\alpha=0.75)$ : cigarettes, alcohol, marijuana, sedatives, stimulants, cocaine, opiates, ecstasy, hallucinogens and inhalants.

\section{Substance use and mental health disorders}

Seven items from the Composite International Diagnostic Interview (CIDI) (World Health Organization, 2008) examined recent substance use and mental health disorders, including alcohol abuse, drug abuse, alcohol dependence, drug dependence, major depressive disorder, mania and post traumatic stress disorder. The CIDI is a comprehensive, structured interview in which respondents are asked about symptoms and diagnoses are calculated in keeping with the DSM-IV (American Psychiatric Association, 1994) and the ICD-10 (World Health 
Organization, 2008). Respondents who met criteria for these disorders within the last year were coded as 1 and all other respondents coded as 0 for each.

\section{Psychological distress}

Two additional measures examined psychological distress and negative emotionality: the Brief Symptom Inventory (BSI) (Derogatis and Melisaratos, 1983) and the Revised Children's Manifest Anxiety Scale (RCMAS) (Reynolds and Richmond, 1985). The BSI is a 53-item inventory in which respondents assess the degree to which they have been bothered ( $0=$ 'not at all' to $4=$ 'extremely') during the previous week by any of 53 symptoms, which yield subscales such as interpersonal sensitivity, depression and somatisation. The RCMAS $(\alpha=0.87)$ is a 28-item measure that examines the degree to which a respondent experiences anxiety across various domains. For both measures, higher scores indicate greater psychological distress.

\section{Psychological factors}

Several psychological factors also hypothesised as associated with TBI were examined in this study, including: psychopathy, moral disengagement, impulsivity, cognitive dysfunction and intelligence. For all psychological factors, higher scores indicate greater levels of the corresponding constructs.

\section{Psychopathy}

The Psychopathy Checklist: Youth Version (Forth et al., 2003) was used. The Psychopathy Checklist: Youth Version $(\alpha=0.87)$ was calculated from a 20 -item questionnaire completed after semi-structured interview by trained interviewers.

\section{Moral disengagement}

The mechanisms of moral disengagement (Bandura et al., 1996) was used to assess the degree of respondents' lack of concerns about the treatment of others. This 32-item index $(\alpha=0.88)$ measured moral disengagement in a variety of domains, including moral justification, displacement of responsibility and dehumanisation.

\section{Impulsivity}

Impulsivity was measured on the impulse control subscale of the Weinberger Adjustment Inventory (Weinberger \& Schwartz, 1990). This 8-item measure $(\alpha=0.76)$ is designed to assess an individual's capacity for self-control; however, this item was reversed coded so that higher scores indicated greater impulsivity or less self-control. 


\section{Cognitive dysfunction}

The Stroop Color and Word Test (Golden, 1978) was used to measure cognitive or neurological dysfunction. The Stroop is a widely-used test employing a variety of reading assessments to examine impairment to the frontal cortex of the brain.

\section{Behavioural factors}

\section{Delinquency}

The measure of delinquency $(\alpha=0.81)$ was comprised of 17 dichotomous items relating to adolescent involvement in nonviolent and violent delinquency during the previous year. These included involvement in behaviours such as shoplifting, drug selling and fighting and also lifetime adolescent gang involvement and bullying behaviour.

\section{Peer delinquency and antisocial influence}

Originally used in the Rochester Youth Study (Thornberry et al., 2003), the measures of peer delinquency $(\alpha=0.92)$ and antisocial influence $(\alpha=0.89)$ examined the degree of antisocial behaviour and negative behavioural influence among an adolescent's peers. For both scales, higher scores indicated greater peer delinquency and antisocial influence, respectively.

\section{Exposure to violence}

A modified version of the Exposure to Violence Inventory (Selner-Ohagan et al., $1998)$ was used to examine violent victimisation $(\alpha=0.62)$ and witness to violence $(\alpha=0.78)$. The victimisation and witness subscales were comprised of six and seven items, respectively, with higher values indicating greater exposure to violence.

\section{Demographic controls}

The following demographic variables were examined: age, gender, race/ethnicity (non-Hispanic white, African American, Hispanic and 'other' race/ethnicity), parent socio-economic status, metropolitan area of residence (Phoenix, Philadelphia) and the presence of a biological father in the home.

\section{Statistical analysis}

First, chi-square tests of association and two group mean comparison tests (e.g. $t$-tests) were used to examine the bivariate associations between head injury and categorical and continuous variables, respectively. Effect sizes for these associations were summarised by means of phi coefficients $(\varphi)$ and Cohen's d (Cohen, 1988). Multivariate logistic regression equation was then used to examine the associations between 
key independent variables identified in bivariate tests and TBI. There were no missing data on TBI. All bivariate and multivariate associations were computed using STATA 12.1 SE (StataCorp, 2011).

\section{Results}

Table 1 shows that adolescents reporting TBI were slightly older than those with no history of TBI $(t=2.54, p<0.05)$, although the effect size for this relationship was small $(d=0.13)$. Significant differences in gender and race are also shown. Male adolescents were significantly more likely to report a TBI $\left(\chi^{2}=12.94, p<0.001\right)$ although, again, the effect size for this relationship was small $(\varphi=0.10)$. NonHispanic white adolescents were disproportionately more likely to report a previous TBI compared with adolescents of all other racial and ethnic backgrounds $\left(\chi^{2}=8.34, p<0.05\right)$, although, again, the effect size was small $(\varphi=0.08)$. No significant differences were observed in terms of parent socio-economic status, city of residence or the presence of a biological father in the home.

Table 2 shows that, across the board, adolescents reporting a previous TBI were significantly more likely to report any substance use $(t=3.53, p<0.001$, $d=0.21)$, and to meet criteria for alcohol $\left(\chi^{2}=5.73, p<0.05, \varphi=0.06\right)$ or drug $\left(\chi^{2}=8.12, p<0.01, \varphi=0.08\right)$ abuse as well as alcohol $\left(\chi^{2}=5.29, p<0.05\right.$, $\varphi=0.06)$ or drug $\left(\chi^{2}=8.36, p<0.01, \varphi=0.08\right)$ dependence, all at the bivariate level. No significant differences were observed for diagnoses of major depression, mania or post traumatic stress disorder, although adolescents who had experienced TBI scored significantly higher on the BSI $(t=4.8$ to, $p<0.001, d=0.30)$ and the RCMAS $(t=4.05, p<0.001, d=0.24)$.

Table 3 displays the bivariate psychological, behavioural and violence exposure correlates with TBI. Adolescents reporting TBIs had significantly higher scores on measures of psychopathy $(t=4.07, p<0.001, d=0.24)$, moral disengagement $(t=2.51, \mathrm{p}<0.05, d=0.14)$ and impulsivity $(t=5.70, p<0.001, d=0.34)$. Adolescents with a history of TBI also reported higher levels of delinquency $\left(t=5.41, p<0.001, d=0\right.$. 32), bullying $\left(\chi^{2}=10.07, p<0.01, \varphi=0.09\right)$, peer delinquency $(t=4.50, p<0.001, d=0$. 26) and peer antisocial influence $(t=4.49, p<0.001, d=0.25)$. Finally, adolescents who reported TBI were significantly more likely also to report violent victimisation $(t=8.99, p<0.001, d=0.52)$ and to have witnessed violence $(t=4.32, p<0.001, d=0.25)$.

Table 4 examines the multivariate associations between TBI as the dependent variable and key independent variables. TBI was about twice as likely to have been reported by male as female adolescents $(\mathrm{OR}=2.08, \mathrm{CI}=1.35-3.22)$, whereas it was significantly less likely to be reported by 'other' racial/ethnic groups than Hispanic of African American groups $(\mathrm{OR}=0.83, \mathrm{CI}=0.70-0.99)$. After controlling for these socio-demographic variables, reported TBI was significantly and independently associated with higher scores on the BSI 


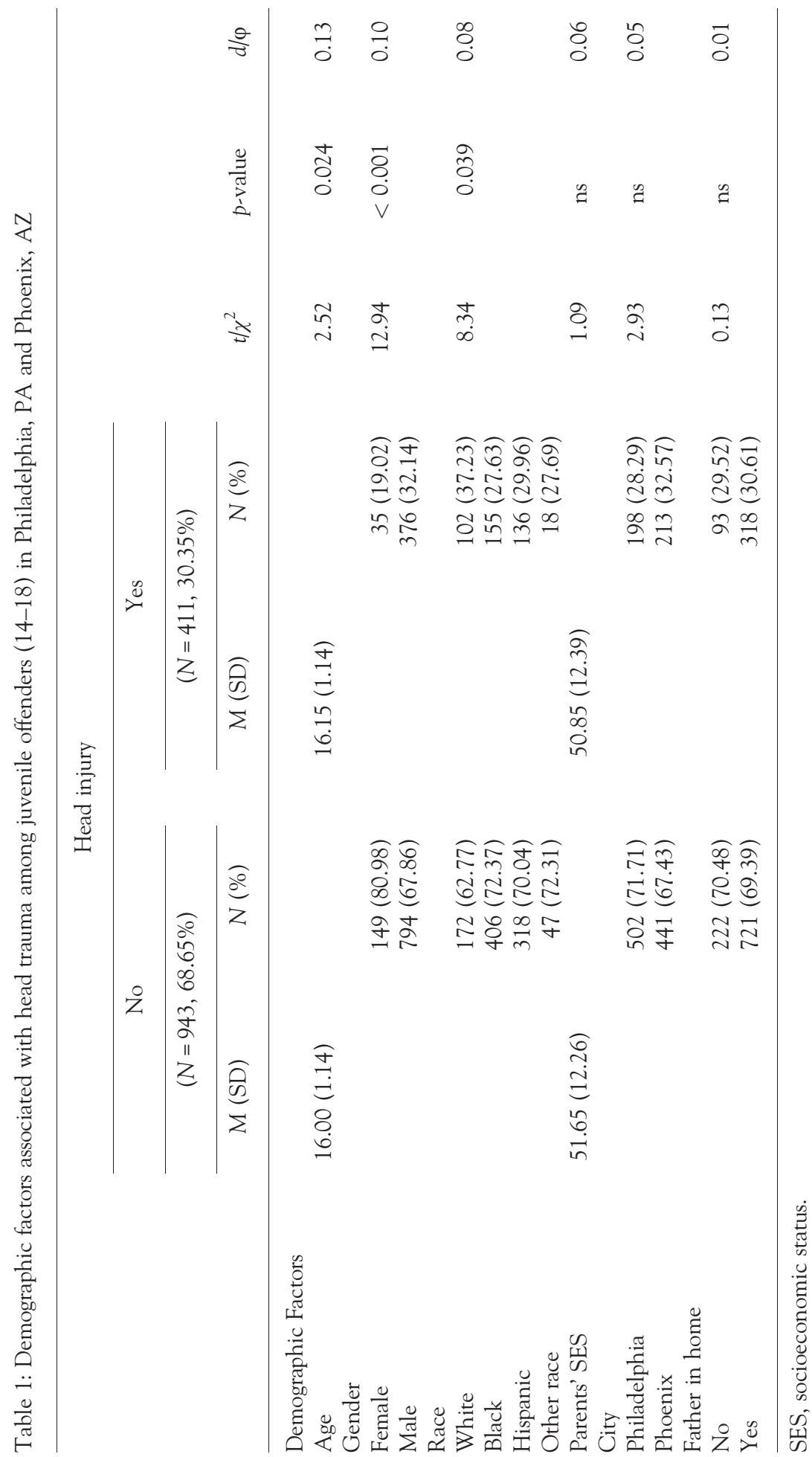




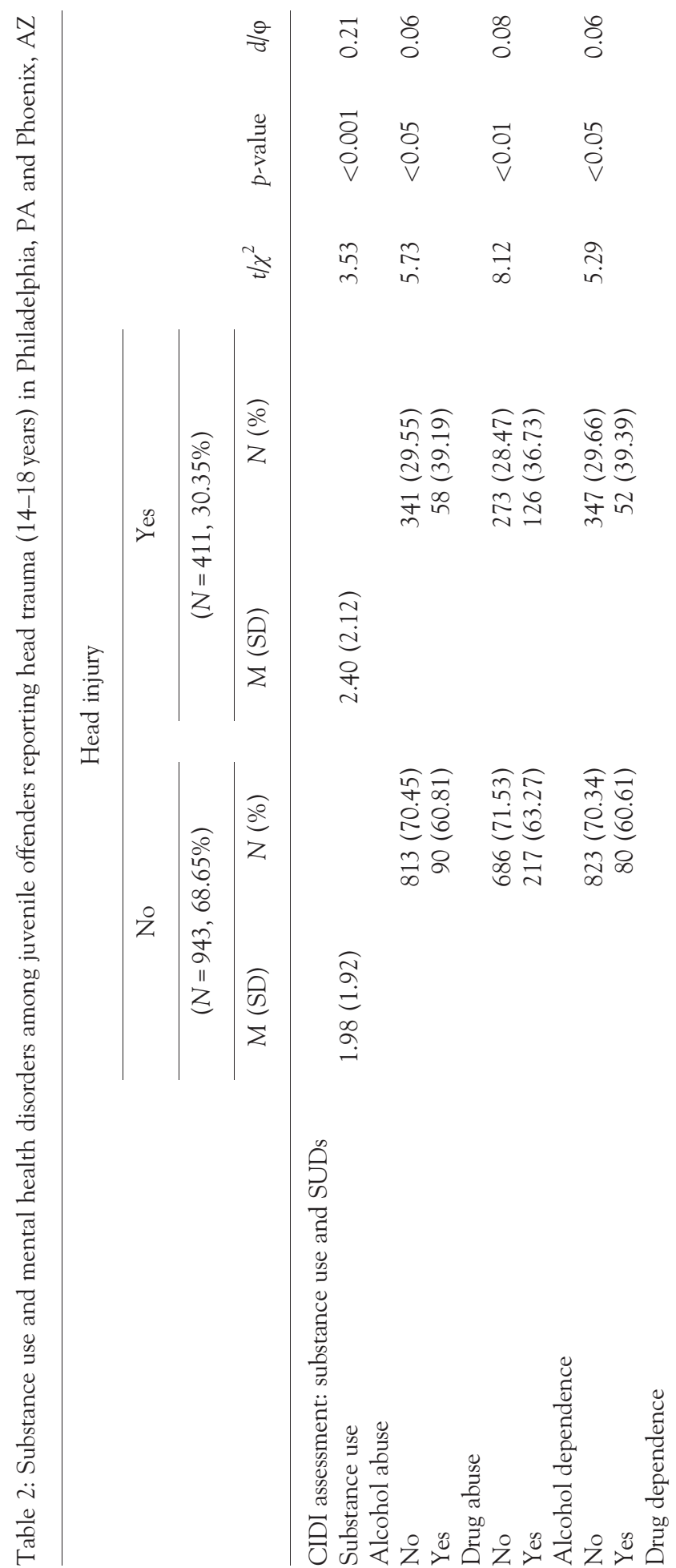




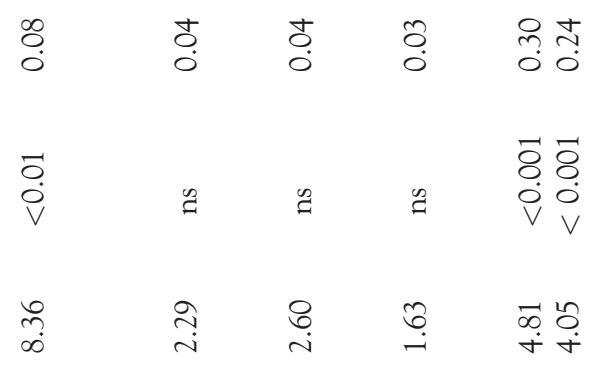

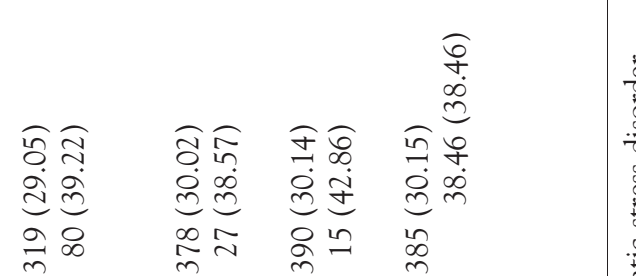

గิ

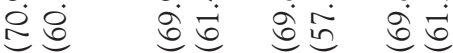

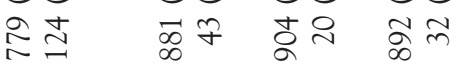

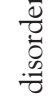

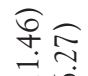

웅

$\Xi \underset{6}{0}$

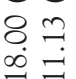

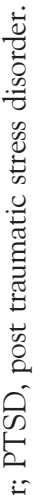

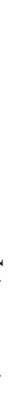




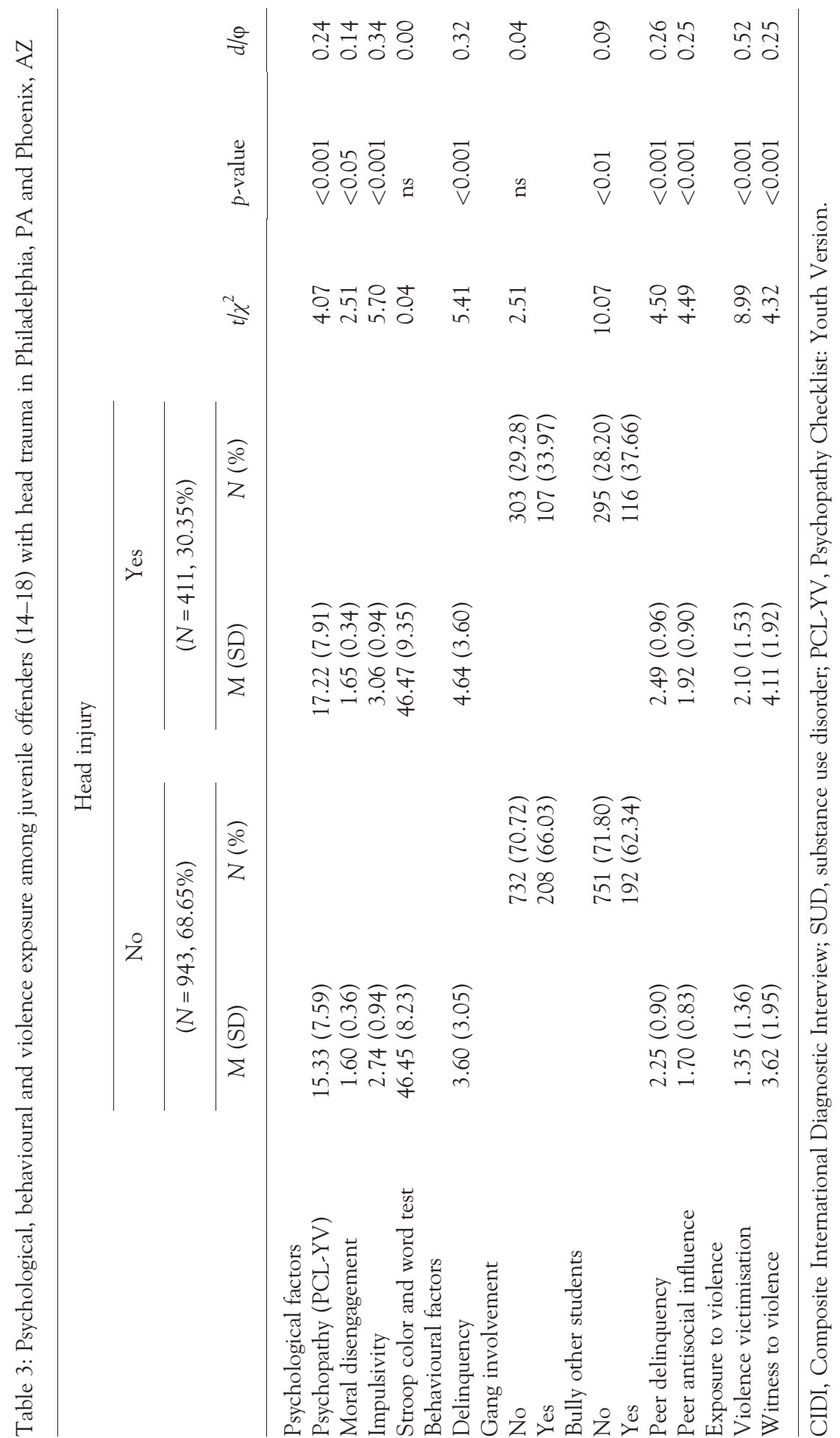


Table 4: Multivariate analyses comparing juvenile offenders (14-18) with and without head trauma in Philadelphia, PA and Phoenix, AZ

\begin{tabular}{lll}
\hline & \multicolumn{2}{c}{ Head trauma } \\
\cline { 2 - 3 } & \multicolumn{1}{c}{ OR } & $95 \%$ CI \\
\hline Sociodemographic control variables & & \\
Age & 1.04 & $(0.93-1.17)$ \\
Gender (male) & $2.08^{* *}$ & $(1.35-3.22)$ \\
Race/ethnicity & & \\
African American & 0.88 & $(0.73-1.06)$ \\
Hispanic & 0.90 & $(0.80-1.02)$ \\
Other & $0.83^{*}$ & $(0.70-0.99)$ \\
Parents' SES & 1.00 & $(0.99-1.01)$ \\
Independent variables & & \\
Brief Symptom Inventory & $1.22^{* *}$ & $(1.06-1.39)$ \\
Psychopathy (PCL-YV) & 0.99 & $(0.85-1.16)$ \\
Moral disengagement & 0.91 & $(0.78-1.05)$ \\
Impulsivity & $1.18^{*}$ & $(1.01-1.37)$ \\
Substance use & 0.95 & $(0.81-1.10)$ \\
Delinquency & 1.08 & $(0.92-1.26)$ \\
Victimisation & $1.45^{* * *}$ & $(1.25-1.69)$ \\
\hline
\end{tabular}

SES; socioeconomic status, PCL-YV; Psychopathy Checklist: Youth Version.

$* p<0.05, * * p<0.01, * * * p<0.001$

$(\mathrm{OR}=1.22, \mathrm{CI}=1.06-1.39)$, greater impulsivity $(\mathrm{OR}=1.18, \mathrm{CI}=1.01-1.37)$ and greater violent victimisation $(\mathrm{OR}=1.45, \mathrm{CI}=1.25-1.69)$.

\section{Discussion}

To our knowledge, our study is the largest investigation of TBI among juvenile offenders. Our finding that about one third of the sample had TBI fits with the results of a recent meta-analysis (Farrer et al., 2012) and is substantially higher than the $12 \%$ identified in the general population of young people (Frost et al., 2013). A Swedish population-based study of adults found that nearly $10 \%$ of people with TBI committed a crime (Fazel et al., 2011). Our primary hypothesis that TBI would be associated with higher levels of impulsivity and negative emotionality was supported, even after controlling for demographic factors (age, gender, socioeconomic status and race/ethnicity) and confounds such as substance use, psychopathy, moral disengagement and prior delinquency. We also confirmed that juvenile offenders with TBI were more likely to report having been a victim of violence or abuse of some kind. Thus, the empirical profile of 
young people is, according to the Philadelphia and Phoenix data we used, not only consistent with theoretical expectations, but also fits with research that has shown that antisocial individuals display an array of neurocognitive, emotional and social deficits (Cox et al., 2013; Defoe et al., 2013; Shaw et al., 2012; Vaughn et al., 2011a, 2011b; Walters and DeLisi, 2013) and have experienced victimisation.

Although odds ratios from the logistic regression may appear small, each increment relates to a unit of measurement on the continuous scales of the impulsivity, negative emotionality and victimisation measures. These effects are clinically meaningful when considering the mean differences in having a history of TBI rather than not. Although, strictly, the study methods were not appropriate for attributing cause and effect, the fact that the TBI was historical and the emotional and behavioural problems currently suggests the possibility that intervention to minimise the residual effects of the TBI could also have an impact on emotions and activities. Criminologists have suggested that neurobiological constructs should be better integrated to criminological theory and research (Armstrong and Boutwell, 2012; Patrick et al., 2012; Rocque et al., 2012; Welsh and Farrington, 2012) to understand the biosocial mechanisms of serious antisociality. We agree with this call for integration, and suggest that TBI is a specific construct that can be measured during criminological data collection efforts. Further, research suggests that managing neuropsychological conditions with medications is associated with reductions in criminality (Lichtenstein et al., 2012).

\section{Limitations}

As with other studies, several limitations should be noted. First, the study data are cross-sectional and determinations regarding the causal status and direction of TBI in relation to study variables cannot be adequately tested. Thus, study participants may already have pre-existing neurocognitive deficits. Second, the assessment of TBI relies on self-report of the juvenile. There was no independent verification of TBI, medical or neuropsychological assessment of the extent of TBI. Thus, we cannot comment on a 'dose-response' curve, as some have (Davies et al., 2012). The fact that the prevalence of TBI in our samples is consistent with those found in prior research provides some external validation of the use of such self-report data. Also worthy of discussion, was that we had no situational or contextual information surrounding the TBI event(s). Such data would be illuminating, as different circumstances of TBI might have different implications, even allowing for similar brain damage - for example, injuries arising from parental or other familial abuse compared with truly accidental injury in the context of a supportive family. Moving forward with research on TBI among enriched and at-risk samples, such as juvenile offenders, it will be useful to examine further the long-term trajectories of youth with TBI compared with non-TBI youth. With respect to policy and practice in the juvenile justice system, it would be valuable to know if these young people fare worse in other aspects of social adjustment in early adulthood. 


\section{Conclusions}

This study extends the generalisability of current understanding of links between $\mathrm{TBI}$ and criminality among young people. We analysed information from a large number (1354) of young offenders from two US sites (Philadelphia, PA and Phoenix, AZ). The evidence supported our hypothesis, based on Moffitt's (1993) taxonomy and self-control theory (Gottfredson \& Hirschi, 1990) that TBI would be associated with impulsivity and negative emotionality, even after allowing for variables, which were associated with higher risk of TBI, such as male sex. In addition, reports of having been victimised in some way were independently associated with such injury. The implications of our findings are that it would be worth screening young offenders for a history of such injury, perhaps, particularly, if they are thought to have had victim experiences.

\section{References}

American Psychiatric Association (1994) Diagnostic and Statistical Manual of Mental Disorders (DSM-IV) (4th ed.). Washington, DC: American Psychiatric Association.

Armstrong TA, Boutwell BB (2012) Low resting heart rate and rational choice: Integrating biological correlates of crime in criminological theories. Journal of Criminal Justice 40: 31-39.

Bandura A, Barbarnelli C, Caprara GV, Pastorelli C (1996) Mechanisms of moral disengagement in the exercise of moral agency. Journal of Personality and Social Psychology 71: 364-374.

Barnes JC, Beaver KM (2010) An empirical examination of adolescence-limited offending: A direct test of Moffitt's maturity gap thesis. Journal of Criminal Justice 38: 1176-1185.

Chung HL, Schubert CA, Mulvey EP (2007) An empirical portrait of community reentry among serious juvenile offenders in two metropolitan cities. Criminal Justice and Behavior 34: $1402-1426$.

Cohen J (1988) Statistical Power for the Behavioral Sciences (2nd ed.). Hillsdale, NJ: Lawrence Erlbaum.

Cox J, Edens JF, Magyar MS, Lilienfeld SO, Douglas KS, Poythress NG Jr (2013) Using the Psychopathic Personality Inventory to identify subtypes of antisocial personality disorder. Journal of Criminal Justice 41: 125-134.

Craswell K, Maughan B, Davis H, Davenport F, Goddard N (2004) The psychosocial needs of young offenders and adolescents from an inner city area. Journal of Adolescence 27: 415-428.

Davies RC, Williams WH, Hinder D, Burgess CNW, Mounce LTA (2012) Self-reported traumatic brain injury and postconcussion symptoms in incarcerated youth. Journal of Head Trauma Rehabilitation 27: E21-E27.

Defoe IN, Farrington DP, Loeber R (2013) Disentangling the relationship between delinquency and hyperactivity, low achievement, depression, and low socioeconomic status: Analysis of repeated longitudinal data. Journal of Criminal Justice 41: 100-107.

DeLisi M (2011) Self-control theory: The Tyrannosaurus rex of criminology is poised to devour criminal justice. Journal of Criminal Justice 39: 103-105.

DeLisi M, Vaughn MG (2008) The Gottfredson-Hirschi critiques revisited: Reconciling selfcontrol theory, criminal careers, and career criminals. International Journal of Offender Therapy and Comparative Criminology 52: 520-537.

Derogatis L, Melisaratos N (1983) The Brief Symptom Inventory: An introductory report. Psychological Medicine 13: 595-605.

Farrer TJ, Frost RB, Hedges DW (2012) Prevalence of traumatic brain injury in juvenile offenders: A meta-analysis. Child Neuropsychology 1-10. DOI: 10.1080/09297049.2011.647901 
Farrington DP, Ttofi MM, Coid JW (2009) Development of adolescence-limited, late-onset, and persistent offenders from age 8 to age 48. Aggressive Behavior 35: 150-163.

Faul M, Xu L, Wald MM, Coronado VG (2010) Traumatic brain injury in the United States: emergency department visits, hospitalizations and deaths 2002-2006. Atlanta: Centers for Disease Control and Prevention, National Center for Injury Prevention and Control.

Fazel S, Lichtenstein P, Grann M, Långström N (2011) Risk of violent crime in individuals with epilepsy and traumatic brain injury: a 35-year Swedish population study. PLoS Medicine 8: e1001150.

Forth A, Kosson D, Hare R (2003) The Hare Psychopathy Checklist: Youth Version, Technical Manual. New York: Multi-Health Systems, Inc.

Frost RB, Farrer TJ, Primosch M, Hedges DW (2013) Prevalence of brain injury in the general adult population: A meta-analysis. Neuroepidemiology 40: 154-159.

Golden C (1978) Stroop Color and Word Test. Chicago, Illinois: Stoelting Company.

Gottfredson MR, Hirschi T (1990) A general theory of crime. Stanford, CA: Stanford University Press.

Jennings WG, Reingle JM (2012) On the number and shape of developmental/life-course violence, aggression, and delinquency trajectories: A state-of-the-art review. Journal of Criminal Justice 40: 472-489.

Langlois J, Rutland-Brown W, Thomas K (2006) Traumatic Brain Injury in the United States: Emergency Department Visits, Hospitalizations, and Deaths. Atlanta, GA: Centers for Disease Control and Prevention, National Center for Injury Prevention.

Lichtenstein P, Halldner L, Zetterqvist J, Sjölander A, Serlachius E, Fazel S, Långström N, Larsson $\mathrm{H}$ (2012) Medication for attention deficit-hyperactivity disorder and criminality. New England Journal of Medicine 367: 2006-2014.

McGuire LM, Burright RG, Williams R, Donovick PJ (1998) Prevalence of traumatic brain injury in psychiatric and non-psychiatric subjects. Brain Injury 12: 207-214.

McKinlay A, Grace RC, Horwood LJ, Fergusson DM, Ridder EM, MacFarlane MR (2008) Prevalence of traumatic brain injury among children, adolescents and young adults: prospective evidence from a birth cohort. Brain Injury 22: 175-181.

Moffitt TE (1993) Adolescence-limited and life-course-persistent antisocial behavior: A developmental taxonomy. Psychological Review 100: 674-701.

Moffitt TE (2003) Life-course-persistent and adolescence-limited antisocial behavior: A 10-year research review and a research agenda. In Lahey BB, Moffitt TE, Caspi A (eds) Causes of Conduct Disorder and Juvenile Delinquency (pp. 49-75). New York: The Guilford Press.

Moffitt TE, Caspi A, Harrington H, Milne BJ (2002) Males on the life-course-persistent and adolescence-limited antisocial pathways: Follow-up at age 26 years. Development and Psychopathology 14: 179-207.

Mulvey EP, Schubert CA (2012) Some initial policy implications from the Pathways to Desistance study. Victims and Offenders 7: 407-427.

Patrick CJ, Durbin CE, Moser JS (2012) Reconceptualizing antisocial deviance in neurobehavioral terms. Development and Psychopathology 24: 1047-1071.

Perron BE, Howard MO (2008) Prevalence and correlates of traumatic brain injury among delinquent youths. Criminal Behaviour and Mental Health 18: 243-255.

Pratt TC, Cullen FT (2000) The empirical status of Gottfredson and Hirschi's general theory of crime: A meta-analysis. Criminology 38: 931-964.

Raine A, Moffitt TE, Caspi A, Loeber R, Stouthamer-Loeber M, Lynam D (2005) Neurocognitive impairments in boys on the life-course persistent antisocial path. Journal of Abnormal Psychology 114: 38-49.

Reynolds CR, Richmond BO (1985) Revised Children's Manifest Anxiety Scale: RCMAS Manual. Los Angeles: Western Psychological Services. 
de Ridder DT, Lensvelt-Mulders G, Finkenauer C, Stok FM, Baumeister RF (2012) Taking stock of self-control: A meta-analysis of how trait self-control relates to a wide range of behaviors. Personality and Social Psychology Review 16: 76-99.

Rocque M, Welsh BC, Raine A (2012) Biosocial criminology and modern crime prevention. Journal of Criminal Justice 40: 306-312.

Schubert CA, Mulvey EP, Cauffman E, Steinberg L, Hecker T, Losoya SH, et al. (2004) Operational lessons from the pathways to desistance project. Youth Violence $\mathcal{F}$ Juvenile Justice 2: 37-255.

Selner-Ohagan M, Kindlon D, Buka S, Raudenbush S, Earls F. (1998) Assessing exposure to violence in urban youth. Journal Of Child Psychology and Psychiatry and Allied Disciplines 39: 215-224.

Shaw DS, Hyde LW, Brennan LM (2012) Early predictors of boys' antisocial trajectories. Development and Psychopathology 24: 871-888.

Shiroma EJ, Ferguson PL, Pickelsimer EE (2010) Prevalence of traumatic brain injury in an offender population: A meta-analysis. Journal of Head Trauma Rehabilitation 27: E1-E10.

StataCorp (2011) Stata Statistical Software: Release 12. College Station, TX: StataCorp LP.

Thornberry TP, Krohn MD, Lizotte AJ, Smith CA, Tobin K (2003) Gangs and Delinquency in Developmental Perspective. New York: Cambridge University Press.

Vaughn MG, Beaver KM, DeLisi M, Perron BE, Schelbe L (2009) Gene-environment interplay and the importance of self-control in predicting polydrug use and substance-related problems. Addictive Behaviors 34: 112-116.

Vaughn MG, DeLisi M, Gunter T, Fu Q, Beaver KM, Perron BE, Howard MO (2011a) The severe 5\%: A latent class analysis of the externalizing behavior spectrum in the United States. Journal of Criminal Justice 39: 75-80.

Vaughn MG, Fu Q, Wernet SJ, DeLisi M, Beaver KM, Perron BE, Howard MO (2011b) Characteristics of abstainers from substance use and antisocial behavior in the United States. Journal of Criminal Justice 39: 212-217.

Walters GD, DeLisi M (2013) Antisocial cognition and crime continuity: Cognitive mediation of the past crime-future crime relationship. Journal of Criminal Justice 41: 135-140.

Welsh BC, Farrington DP (2012) Science, politics, and crime prevention: Toward a new crime policy. Journal of Criminal Justice 40: 128-133.

Weinberger DA, Schwartz GE (1990) Distress and restraint as superordinate dimensions of selfreported adjustment: a typological perspective. Journal of Personality 58(2): 381-417.

Williams WH, Cordan G, Mewse AJ, Tonks J, Burgess CNW (2010) Self-reported traumatic brain injury in male young offenders: a risk factor for re-offending, poor mental health and violence? Neuropsychological Rehabilitation 20: 801-812.

World Health Organization (2008) ICD-10: International Statistical Classification of Diseases and Related Health Problems (10th Rev. ed.). New York, NY: World Health Organization.

Address correspondence to: Michael G. Vaughn, School of Social Work, Saint Louis University, 3550 Lindell BLVD St. Louis 63103, MO, USA.

Email: mvaughn9@slu.edu 